Rev Biomed 2001; 12:218-220.

\title{
La Bronquiolitis... ¿Produce asma?
}

Carta al Editor

Eduardo A. Lara-Pérez.

Hospital de Gineco-Pediatría No. 71, Instituto Mexicano del Seguro Social. (I.M.S.S.) Veracruz, Veracruz, México.

E1 40 a $70 \%$ de los lactantes con bronquiolitis viral aguda presentan sibilancias durante los 2 a 3 años siguientes en el curso de las infecciones respiratorias (1). La causa de estos episodios recurrentes de obstrucción bronquial tras la bronquiolitis no está suficientemente establecida. Algunos estudios señalan que los lactantes que desarrollan una bronquiolitis y a continuación cuadros posteriores de sibilancias, es porque presentan una respuesta inmunoalérgica $\mathrm{Th}_{2}(2) \mathrm{o}$ un desequilibrio inmunológico que se expresaría desde el nacimiento por una baja tasa de IL-12 (3).

Desde el punto de vista inmunológico se han investigado los posibles factores que inciden en el desarrollo de sibilancias recurrentes posbronquiolitis. Se describen como factores predictores de dos o más episodios de sibilancias en el primer año de la vida $(4,5)$, los siguientes:

El tabaquismo gestacional (RR 1,83; IC 95 $\%$ 1,12-3,00).

Las enfermedades de la vía respiratoria intermedia e inferior (crup, bronquitis, bronquiolitis o neumonía) (RR 2,25; IC $95 \%$ 1,58-3,19).

El bajo peso neonatal (RR 1,28; IC $95 \%$ 1,04-1,58 para una diferencia intercuartil)

La carga antigénica intradomiciliaria elevada (RR 1,76; IC $95 \%$ 1,20-2,57).

Cuando se estudia la hiperrespuesta bronquial años después de haber sido hospitalizado un lactante por bronquiolitis secundaria a infección por virus respiratorio sincitial (VRS), una parte importante tienen hiperrespuesta bronquial (HRB). Sin embargo, si el estudio de la HRB se efectúa antes del año de la bronquiolitis, no hay hiperrespuesta bronquial (6). Esta discrepancia en los resultados puede deberse a la metodología empleada, tanto en los aspectos farmacológicos como funcionales. Como determinantes de la HRB, los factores de mayor peso parecen ser son la exposición al humo del tabaco y/o la historia familiar en primer grado de atopia.

Se ha sugerido que las infecciones virales pueden inducir asma. Los virus pueden inducir respuestas inflamatorias de características muy

Solicitud de sobretiros: Dr. Eduardo A. Lara-Pérez, Pedro de Alvarado 201, Frac. Reforma, C.P. 91919, Veracruz, Ver., México. 


\section{EA Lara-Pérez.}

similares al asma, produciendo infiltrados celulares formados por eusinófilos y diversos mediadores bioquímicos, responsables ambos de la obstrucción de la vía aérea. Algunos virus actúan facilitando la capacidad de respuesta inflamatoria que tiene los sujetos atópicos; otros, modificando la respuesta bronquial que expresa la atopia. La respuesta inmunológica a la infección viral puede ser el marcador de desarrollo de atopia (7).

La producción de citocinas durante la bronquiolitis aguda se asocia con el desarrollo posterior de asma. La baja producción de IFN-g durante la bronquiolitis es un indicador de disminución de la función pulmonar $\left(\mathrm{V}_{\text {máx }} \mathrm{FRC}\right) \mathrm{y}$ también de la HRB a la histamina posbronquiolitis (8).

La proteína catiónica del eusinófilo (ECP) y los eusinófilos totales en sangre periférica, no son variables predictivas de asma cuando se miden en un primer episodio de bronquiolitis. Por el contrario, sí lo son cuando se estudian tres años después de la bronquiolitis aguda (9).

Hay relación entre la infección por VRS y los mecanismos de control neural de la vía aérea (adrenérgico, colinérgico, inhibidor no adrenérgico no colinérgico y facilitador no adrenérgico no colinérgico). El VRS produce cambios agudos y crónicos en el control neural de la vía aérea en modelos animales. Si la infección sucede en edades tempranas, la lesión tiende a persistir a largo plazo (10). Otros investigadores señalan que la bronquiolitis no es la responsable de daño permanente en la vías aéreas bajas, sino que hay evidencia de que la función pulmonar es anormal antes de la bronquiolitis (11).

El sexo masculino, la atopia parental y el tabaquismo materno durante la gestación, son los factores de mayor peso para desarrollar asma en los primeros años de la vida (12), siempre y cuando exista una alteración o susceptibilidad genética especifica (13). En cambio, la variable bronquiolitis aguda del lactante VRS (+), es un factor de riesgo independiente para desarrollar sibilancias en edades inferiores a 11 años y esta asociación es independiente de la atopia, es decir, el VRS no sería un factor implicado en el desarrollo de atopia posterior (14). Por tanto, no está clara la asociación entre bronquiolitis (infección por VRS) y asma: para el desarrollo de asma pesa más la exposición a altas concentraciones de alergenos en las primeras etapas de la vida que la infección por VRS (15).

Como conclusión hay que señalar que la mayoría de los lactantes que sibilan después de una bronquiolitis ${ }^{16}$, presenta esta patología de modo transitorio, limitada en el tiempo, ligada a la disminución de la función pulmonar presente desde el nacimiento, sin presentar riesgo aumentado para desarrollar asma o alergia posteriormente. En un número muy pequeño de casos, los episodios repetidos de sibilancias están relacionados con asma.

Palabras clave: Bronquiolitis, asma, infecciones respiratorias.

\section{REFERENCIAS.}

1.- Murray M, Webb MS, O'Callaghan C, Swarbrick AS, Milner AD. Respiratory status and allergy after Bronchiolitis. Arch Dis Child. 1992; 67: 482-7.

2.- Renzi PM, Turgeon JP, Yang JP, Drblik SP, Marcotte JE, Pedneualt L. Cellular immunity is activated and a TH2 response is associated with early wheezing in infants after Bronchiolitis. J Pediatr. 1997; 130: 584-93.

3.- Blanco-Quirós A, González H, Arranz E, Lapeña S. Decreased interleukin-12 levels in umbilical cord blood in children who developed acute Bronchiolitis. Pediatr Pulmunology. 1999; 28: 175-80.

4.- Korppi M, Reijonen T, Poysa L, Juntunen-Backman K. A 2- to 3- year outcome after Bronchiolitis. Am J Dis Child. 1993; 147: 628-31.

5.- Golg DR, Burge HA, Carey V, Milton DK, Platts-Mill T, Weiss ST. Predictors of repeated wheeze in the first year of life. The relative roles of cockroach, birth weight, acute lower respiratory illness, and maternal smoking. Am J Respir Crit Care Med. 1999; 160: 227-36.

6.- Kattan M. Epidemiologic evidence of increased airway reactivity in children with a history of Bronchiolitis. J

\section{Revista Biomédica}


Pediatr. 1999; 135: S8-S13.

7.- Welliver RC. Immunologic mechanisms of virusinduced wheezing and asthma. J Pediatr. 1999; 135: S14S20.

8.- Renzi PM, Turgeon JP, Marcotte JE, Drblik SP, Berube $\mathrm{D}$, Gagnon MF. Reduced interferon-gamma production in infants with Bronchiolitis. Am J Respir Crit Care Med. 1999; 159: 1417-22.

9.- Oymar K, Bjerknes R. Is serum eosinophil cationic protein in bronchiolitis a predictor of asthma ?. Pediatr Allergy Immunol. 1998;; 9: 204-7.

10.- Larsen GL, Colasurdo GN. Neural control mechanisms within airways: Disruption by respiratory syncytial virus. J Pediatr. 1999; 135: S21-S27.

11.- Young S, O’Keefe PT, Arnott J, Landau LI. Lung function, airway responsiveness, and respiratory symptoms before and after bronchiolitis. Arch Dis Child. 1995; 72: 16-24.

12.- Sears MR, Holdaway MD, Flannery EM, Herbison GP, Silva PA. Parenteral and neonatal risk factors for atopy, airway hyper-responsiveness, and asthma. Arch Dis Child, 1996; 75: 392-8.

13.- Postma DS, Bleecker ER, Amelung PJ, Holroyd KJ, $\mathrm{Xu}$ J, Panhuysen CIM. Genetic susceptibility to asthma bronchial hyperresponsiveness coinherited with a major gene for atopy. N Engl J Med. 1995; 333: 894-900.

14.- Stein RT, Sherrill D, Morgan WJ, Holberg CJ, Halonen M, Taussig LM. Respiratory syncytial virus in early life and risk of wheeze and allergy by age 13 years. Lancet. 1995; 354: 541-5.

15.- Welliver RC. RSV and chronic asthma. Lancet. 1995; 34: 789-90.

16.- Godfrey S. Bronchiolitis and asthma in infancy and early childhood. Thorax. 1996;5 (Suppl 2): S60-S64. 